\title{
Fruit and vegetable consumption and the metabolic syndrome: a systematic review and dose-response meta-analysis
}

\author{
Mijin Lee, Miso Lim and Jihye Kim* \\ Department of Medical Nutrition, Graduate School of East-West Medical Science, Kyung Hee University, Yongin 17104, \\ Republic of Korea \\ (Submitted 20 October 2018 - Final revision received 31 May 2019 - Accepted 28 June 2019; First published online 13 September 2019)
}

\begin{abstract}
A systematic review and meta-analysis of observational studies were performed to assess the dose-response associations between fruit or vegetable consumption and the chance of the metabolic syndrome (MetS). Studies on the association between fruit or vegetable consumption and the risk of the MetS published from January 1958 to 30 October 2018 were searched using the PubMed, MEDLINE and Embase databases, and the references of relevant articles were reviewed. Random-effects models were used to estimate the summary OR with $95 \%$ CI for the MetS, and dose-response analysis was conducted to quantify the associations. Heterogeneity among studies was evaluated using $Q$ and $I^{2}$ statistics. A total of nine observational studies (seven cross-sectional studies and two cohort studies) were included in the meta-analysis. In a dose-response analysis of cohort studies and cross-sectional studies, the summary estimate of the MetS for an increase of $100 \mathrm{~g} / \mathrm{d}$ in fruit consumption (nine studies) was 0.97 (95\% CI 0.95, 0.99; $I^{2}=26.7 \%$ ), whereas an increase of $100 \mathrm{~g} / \mathrm{d}$ in vegetable consumption (nine studies) was not associated with a reduction in the MetS (OR 0.98; $95 \% \mathrm{CI} 0 \cdot 96,1 \cdot 01 ; I^{2}=54.6 \%$ ). In conclusion, an increased intake of fruit may reduce the risk of the MetS. For future research, prospective studies or randomised clinical trials are needed to identify the effects of fruits and vegetables by variety on the risk of the MetS.
\end{abstract}

Key words: Dose-response meta-analyses: Fruit: Vegetables: Metabolic syndrome

The metabolic syndrome (MetS) is a cluster of conditions including abdominal obesity, dyslipidaemia, elevated blood pressure and insulin resistance, which together increase the risk of CVD and type 2 diabetes $^{(1)}$. With its rapidly increasing prevalence in recent decades, the MetS has been regarded as an important public health issue affecting approximately $30-40 \%$ of the population in developed countries in parallel with obesity and diabetes $^{(2)}$.

Diet plays a critical role in the development of the $\mathrm{Met}^{(3)}$. Fruits and vegetables are important components of the diet, and low intake of fruits and vegetables is a risk factor for many chronic diseases, such as cancer and CVD, because fruits and vegetables contain abundant minerals, vitamins and phytochemicals ${ }^{(4)}$.

Epidemiological studies have evaluated the relationship between fruit and vegetable intake and risk of the MetS. However, the results remain controversial. Some studies ${ }^{(5,6)}$ have reported that fruit consumption is significantly associated with a decreased risk of the MetS, while others ${ }^{(7-9)}$ have shown no association between fruit intake and risk of the
MetS. Several studies ${ }^{(9)}$ revealed an inverse association between vegetable intake and risk of the MetS, while others ${ }^{(7,10)}$ showed no relationship.

Two meta-analyses have shown a significant relationship between fruit or/and vegetable consumption and the MetS ${ }^{(11,12)}$. However, these studies only identified the relationship between fruit or/and vegetable consumption and risk of the MetS in the highest $v$. lowest categories of food consumption. The data provided by the dose-response meta-analysis would be useful for determining the right level of fruit or vegetable consumption for the prevention of the MetS, through the evaluation of the linear and non-linear relationships. To the best of our knowledge, no studies have investigated the dose-response relationship between fruit or vegetable consumption and risk of the MetS.

Therefore, we performed a systematic review and metaanalysis combining available data from observational studies to examine the dose-response relationship between fruit or vegetable consumption and chance of the MetS.

Abbreviations: LFK, Luis Furuya-Kanamori; MetS, metabolic syndrome; RR, relative risk.

* Corresponding author: J. Kim, fax +82 31204 8119, email kjhye@khu.ac.kr 


\section{Methods}

Registry and protocol

The protocol for this systematic review with meta-analysis was not registered in a trial registry. The present study followed the Meta-Analysis of Observational Studies in Epidemiology (MOOSE) guidelines.

\section{Literature search strategy}

Two investigators (M. L. and M. L.) searched the literature independently. A systematic literature search was conducted using the PubMed, MEDLINE and Embase databases for articles published from June 1958 to October 2018. The following search terms were used: ('fruit' or 'vegetable') and ('metabolic syndrome' or 'metabolic syndrome X' or 'insulin resistance'). The PubMed search used the medical subject heading terms 'metabolic syndrome', 'metabolic syndrome X' and 'insulin resistance'. In addition, references from the articles retrieved and previous review articles or meta-analyses were reviewed to identify additional relevant studies. The references were stored in EndNote X7 (Clarivate Analytics).

\section{Study selection}

Studies have to be observational (cross-sectional, case-control, cohort study), have fruit or vegetable consumption as the exposure variables, have the MetS as the outcome, report OR or relative risk (RR) and their $\mathrm{CI}$ in humans and to be published in English language journals. If duplicate publications from the same study were identified, the result with the largest number of cases from the study was included. At first, titles and abstracts were reviewed, and then full texts were reviewed.

Two investigators (M. L. and M. L.) reviewed all identified studies independently, and discrepancies were discussed and resolved by a third investigator (J. K.).

\section{Data extraction and quality assessment}

Two investigators (M. L. and M. L.) conducted study selection and data extraction and held further discussion to resolve any disagreement after reviewing the original article. The following data were extracted from each study: first author's name, publication year, study location, study design, follow-up period, number of subjects and cases, age and sex of subjects, dietary assessment method, MetS criteria, OR/RR with 95\% CI for the MetS across dietary intake levels and adjusted variables. The most-adjusted model among the multivariable adjustment models was used.

Two investigators (M. L. and M. L.) independently evaluated the quality of cohort and cross-sectional studies using the modified Newcastle-Ottawa quality assessment scale ${ }^{(13)}$ for the following criteria: representativeness of the sample, justification of sample size, non-respondents, ascertainment of the risk factor, comparability of subjects and clear description of the statistical test. The evaluation scores ranged from 0 to 10 . Total scores $\geq 7$ (out of 10) indicated high quality. Any discrepancies in quality assessment between the two reviewers were resolved by discussion until a consensus was reached. To avoid selection bias, no study was rejected because of these quality criteria.

\section{Statistical analysis}

The effect size from each study was estimated from OR, and the RR for one study was deemed equivalent to OR. For the linear or non-linear dose-response analysis, the natural logarithm of the OR from each study was pooled using random-effect models, which incorporate both within-study and between-study variations ${ }^{(14)}$. If a study reported the estimates separately according to individual fruits or vegetables ${ }^{(15-17)}$ or $\operatorname{sex}^{(6)}$, the effect estimates in the same study were combined using a random-effect model in the main analysis.

The dose-response association between dietary factor (fruit or vegetables) and outcome (MetS) was examined using generalised least-square trend estimation analysis to estimate the study-specific slope lines first and then derive an overall slope, which requires the number of cases and subjects ${ }^{(18,19)}$. When these numbers were not available, variance-weighted leastsquares meta-regression analysis was used to estimate the dose-response slopes ${ }^{(18,19)}$. For these two analyses, the median or mean value for each category of intake level was used. For studies not providing the median or mean intake of each category, the mid-point of the upper and lower boundaries in each category was used as the average intake. Fruit or vegetable consumption reported as servings or times per $\mathrm{d}$ or week was converted to $\mathrm{g} / \mathrm{d}$.

To visualise and summarise the associations between fruit or vegetable consumption and the MetS, the OR from each study as well as a pooled OR are presented as forest plots, where the size of the data markers (squares) corresponds to the inverse of the variance of the natural logarithm of OR from each study and the diamond indicates a pooled OR.

A two-stage random-effects dose-risk meta-analysis was performed to examine a non-linear dose-response relationship between fruit or vegetable consumption and the MetS. After modelling fruit consumption using restricted cubic splines with three knots at fixed percentiles $(10,50,90 \%)$ of the distribution $^{(20-22)}$, a generalised least-squares method and multivariate maximum-likelihood method were used to estimate a summary non-linear dose-response relationship while taking random effects into account ${ }^{(19)}$. A $P$ value for non-linearity was calculated by testing the null hypothesis that the coefficient of the second spline was equal to 0 .

A subgroup analysis and a meta-regression analysis were conducted to explore potential sources of heterogeneity and compare them among groups. The analyses were performed according to study design (cohort/cross-sectional), study location (Asia/Europe), MetS criteria (National Cholesterol Education Program Adult Treatment Panel III and others), study quality (good and others) and adjustment factors (alcohol, smoking, physical activity, education, family history of diabetes, energy intake and meat intake). A sensitivity analysis was conducted in which one study at a time was removed and the remaining studies were assessed to evaluate the impact of the removed study. To explore the presence of heterogeneity and inconsistency, the $Q$ test and $I^{2}$ statistic $(100 \% \times(Q-\mathrm{df}) / Q)$ were 
calculated $^{(23,24)}$. The assumption of heterogeneity was considered valid for $P$ values $<0 \cdot 10$ based on the $Q$ statistic. To estimate the between-study variance, the $\tau^{2}$ statistic was calculated.

Potential small study effects were evaluated by visual inspection of the funnel plot with a pseudo $95 \%$ CI that was tested by Egger's regression asymmetry test ${ }^{(25)}$. The results were considered to indicate a small study effect when the $P$ value was $<0 \cdot 10^{(26)}$. In addition, the Doi plot and the Luis FuruyaKanamori (LFK) index were implemented for the detection of asymmetry of a small study effect ${ }^{(27)}$. Statistical analysis was performed using Stata/SE 14.2 (STATA). The LFK index has been implemented into MetaXL version 5.3 (EpiGear International). A two-tailed $P$ value $<0.05$ was considered statistically significant.

\section{Results \\ Literature search for dose-response meta-analysis}

Originally, 2421 papers were searched and 1024 duplications were excluded. Three articles were added from bibliography review. In total, 1092 articles were excluded based on title and abstract (online Supplementary Table S1). Full-text of 308 articles was reviewed and the following 299 articles were excluded (online Supplementary Table S2): 119 studies not related to dietary factors, seventy-seven studies not related to outcome, twenty-four reviews or letters, thirty-eight studies for which no full text was available, twenty-two studies that did not report OR/RR or $95 \% \mathrm{CI}$, eight studies not published in English, six studies that did not report data for fruit or vegetable consumption, two clinical studies, one duplicate study and two studies that focused on patients with specific diseases. As a result, a total of nine articles ${ }^{(5-10,15,17,20)}$ were identified as eligible for the present meta-analysis (Fig. 1).

\section{Study characteristics}

Nine studies ${ }^{(5-10)}$ including seven cross-sectional studies ${ }^{(5-7,16,17)}$ and two cohort studies ${ }^{(8,15)}$ were used in the dose-response meta-analysis of the association between fruit or vegetable consumption and chance of the MetS (Table 1). Six studies ${ }^{(5,8-10,15,17)}$ were conducted in Asia, and three studies ${ }^{(6,7,16)}$ were conducted in Europe. Seven studies ${ }^{(5-8,10,15,16)}$ included both male and female participants, and two studies ${ }^{(9,17)}$ included only male or female participants. Four studies ${ }^{(6,7,9,17)}$ defined the MetS according to the guidelines of the National Cholesterol Education Program Adult Treatment Panel III ${ }^{(28)}$, and three studies $^{(5,10,15)}$ defined the MetS using the modified National Cholesterol Education Program Adult Treatment Panel III criteria. One study ${ }^{(8)}$ defined the MetS using criteria of the International Diabetes Federation ${ }^{(29)}$. One study ${ }^{(16)}$ defined the MetS as the presence of two out of four criteria considered in diagnostic investigation (diabetes, obesity, dyslipidaemia and hypertension). Most studies were adjusted for age ${ }^{(5-10,17)}$ and smoking ${ }^{(6-9,15-17)}$. Two studies provided the adjusted OR for alcohol $^{(6,8)}$. Four studies provided the adjusted OR for education $^{(5,6,8,15)}$. Four studies ${ }^{(7,8,16,17)}$ received a score indicating high quality.
Dose-response meta-analysis on the chance of the metabolic syndrome associated with fruit and vegetable consumption

Nine studies ${ }^{(5-10,15-17)}$ involving 8422 cases and 38188 participants investigated the association between fruit or vegetable consumption and the MetS. In the dose-response meta-analysis, an increase of $100 \mathrm{~g} / \mathrm{d}$ of fruit intake was associated with $3 \%$ lower odds of the MetS (OR 0.97; $95 \%$ CI 0.95, 0.99), with no statistically significant heterogeneity ( $\left.I^{2}=26.7 \%, \quad P=0.21 ; \quad \tau^{2}=0.0002\right)$ (Fig. 2). Compared with people who had no daily consumption of fruit, the estimated OR of the MetS were 0.97 (95\% CI 0.95, 0.99) for $50 \mathrm{~g} / \mathrm{d}, 0.95$ (95\% CI 0.91, 0.99) for $100 \mathrm{~g} / \mathrm{d}$ (one serving), 0.88 (95\% CI $0.78,0.97$ ) for $200 \mathrm{~g} / \mathrm{d}, 0.81$ (95\% CI $0.69,0.94)$ for $300 \mathrm{~g} / \mathrm{d}, 0.75$ (95\% CI 0.58, 0.92) for $400 \mathrm{~g} / \mathrm{d}, 0.69$ (95\% CI 0.50 , 0.88 ) for $500 \mathrm{~g} / \mathrm{d}$ and 0.66 (95\% CI $0.44,0.88$ ) for $600 \mathrm{~g} / \mathrm{d}$ (Fig. 3(a)). However, there was no evidence of a non-linear relationship between fruit intake and the MetS in the cubic spline model ( $P$ non-linearity $=0 \cdot 25$ ); therefore, a weighted linear regression model was fitted (Fig. 3(b)).

Nine studies ${ }^{(5-10,15-17)}$ involving 8422 cases and 38188 participants investigated the association between vegetable consumption and the MetS. One study ${ }^{(15)}$ revealed an inverse association, while the other eight studies ${ }^{(5-10,16,17)}$ indicated no relationship. In a dose-response analysis, an increase of $100 \mathrm{~g} / \mathrm{d}$ of vegetable intake was not associated with odds of the MetS (OR 0.98; $95 \%$ CI $0.96,1.01)$, with moderate heterogeneity $\left(I^{2}=54.6 \%\right.$, $\left.P=0.02 ; \tau^{2}=0.0005\right)$. There was no evidence of a non-linear association between vegetable intake and the MetS in the cubic spline model $(P$ non-linearity $=0 \cdot 35)$.

\section{Subgroup, meta-regression and sensitivity analyses}

Results for the subgroup analyses and meta-regression analyses of fruit consumption and chance of the MetS are shown in Table 2. Cross-sectional studies showed significant inverse associations (OR 0.97; $95 \%$ CI 0.94, 0.99), while cohort studies showed a non-significant inverse association; however, the difference was not significant $(P=0 \cdot 21)$. Asian studies (OR 0.95; $95 \%$ CI 0.91, 0.99) showed significant inverse associations, while European studies showed a non-significant inverse association; however, the difference was not significant $(P=0.55)$. Subgroup analyses found no significant difference in the MetS criteria $(P>0.3$ for all comparisons). Study quality $(P=0 \cdot 07)$ and adjustment factors such as smoking $(P=0.01)$ and physical activity $(P=0.01)$ seemed to contribute to the heterogeneity in this analysis. With regard to the adjustment factors, such as alcohol, education, family history of diabetes, energy intake and meat intake, no significant differences were found based on the results of metaregression analyses ( $P>0 \cdot 1$ for all comparisons). When one study was deleted from the model at a time, the summary OR ranged from 0.96 (95\% CI 0.93, 0.99) to 0.98 (95\% CI 0.96, 1.00).

Subgroup and meta-regression analyses of vegetable intake and the MetS are shown in Table 3. The subgroup analyses found no significant difference in study design, study location, the MetS criteria, the quality assessment of studies $(P \geq 0 \cdot 1$ for all comparisons) and adjustment factors $(P \geq 0 \cdot 1$ for all comparisons). In the sensitivity analysis of vegetable intake and the MetS, the summary OR ranged from 0.97 (95\% CI 0.93, 1.01) to 

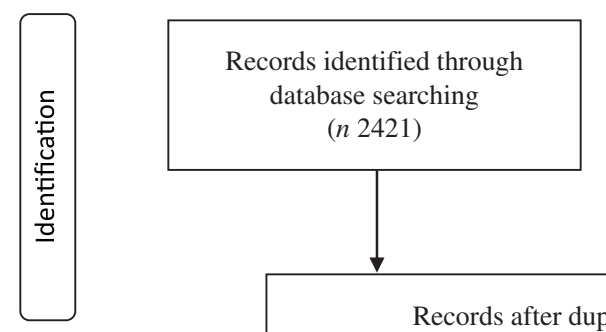

Additional records identified through bibliography review (n 2421) (n 3)

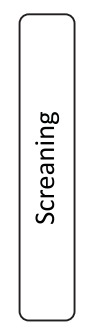

Records after duplicates removed (n 1400)
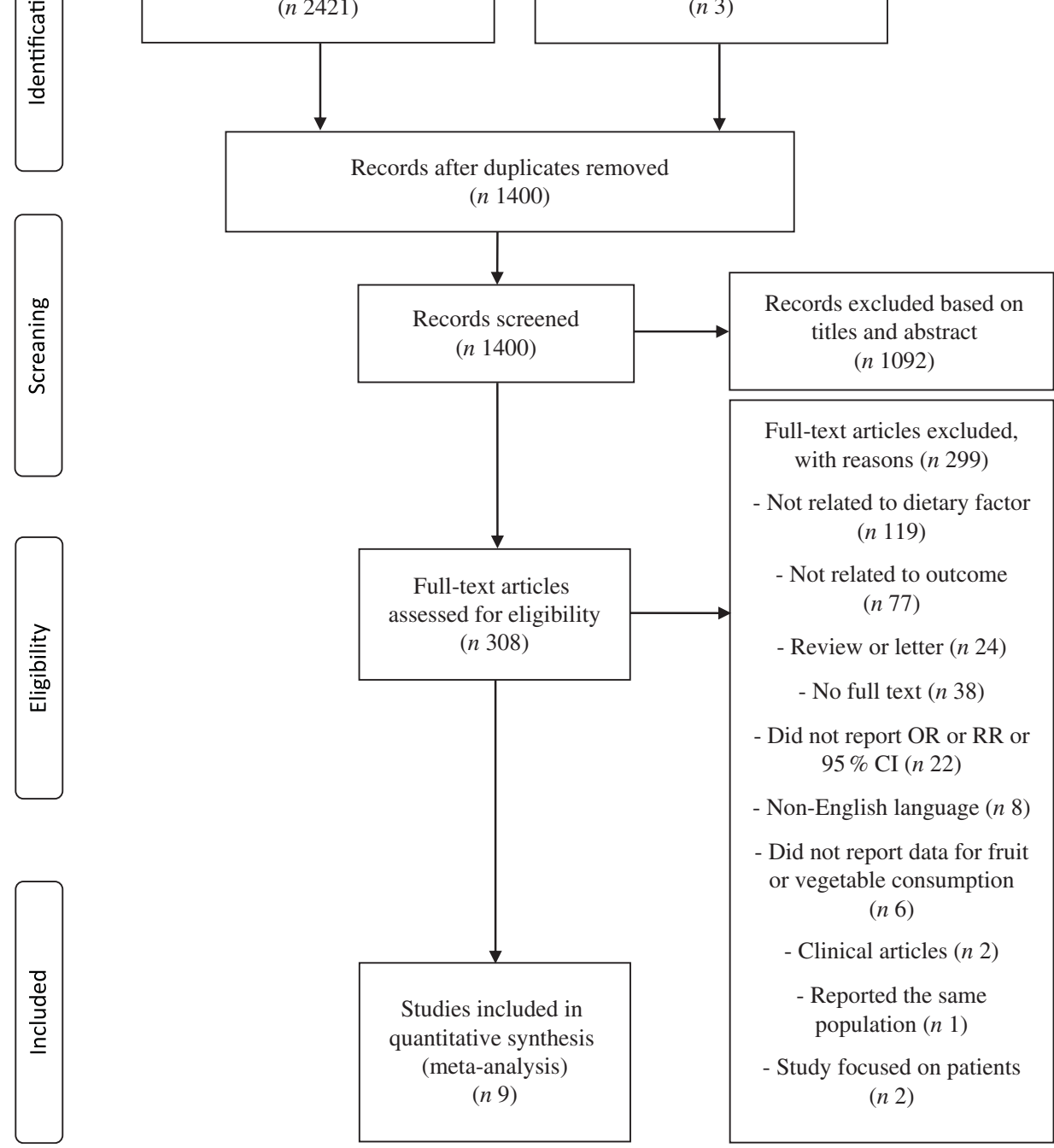

Fig. 1. Flow chart of the selection process according to the Preferred Reporting Items for Systematic Reviews and Meta-Analyses (PRISMA) statement. RR, relative risk.

1.00 (95\% CI 0.99, 1.01). When one study ${ }^{(15)}$, by Cheraghi et al., was excluded, the significance for heterogeneity disappeared $\left(I^{2}=0.0 \%, P=0.77\right)$, and the same result was obtained (OR 1.00 per $100 \mathrm{~g} / \mathrm{d} ; 95 \%$ CI 0.99, 1.01).

\section{Small study effect}

There was no indication of a small study effect for a doseresponse meta-analysis of fruit consumption and the MetS based on Egger's test (Egger's $P=1 \cdot 00$ ), but an LFK index indicated evidence of a study effect (LFK index $=-5 \cdot 78$ ). For vegetable consumption, the test revealed evidence of a small study effect (Egger's $P=0.03$, LFK index $=-2 \cdot 62$ ).

\section{Discussion}

This meta-analysis of seven cross-sectional studies and two cohort studies revealed an inverse relationship between fruit consumption and chance of the MetS. The association between fruit consumption and the MetS was linear; no non-linear association was found. In a dose-response meta-analysis, an increment of $100 \mathrm{~g} / \mathrm{d}$ in fruit consumption was related to a $3 \%$ lower risk of the MetS. Vegetable consumption (nine studies) was not associated with risk of the MetS.

These results are consistent with the findings from previous studies showing the beneficial association of fruit consumption with the incident MetS in the highest $v$. lowest categories of an observational meta-analysis ${ }^{(11,12)}$. A meta-analysis of sixteen studies including thirteen cross-sectional and three cohort studies showed that fruit consumption was associated with a significantly decreased OR for the MetS. The summary OR for the MetS was 0.87 (95\% CI 0.82, 0.92) for fruit consumption $^{(11)}$. A meta-analysis of twenty-six observational studies including twenty cross-sectional, one case-control and five cohort studies reported that the summary OR for the MetS in the highest category of fruit consumption compared with that 


\section{NS British Journal of Nutrition}

Table 1. Characteristics of studies on the association between fruit and vegetable consumption and the Metabolic syndrome (MetS)

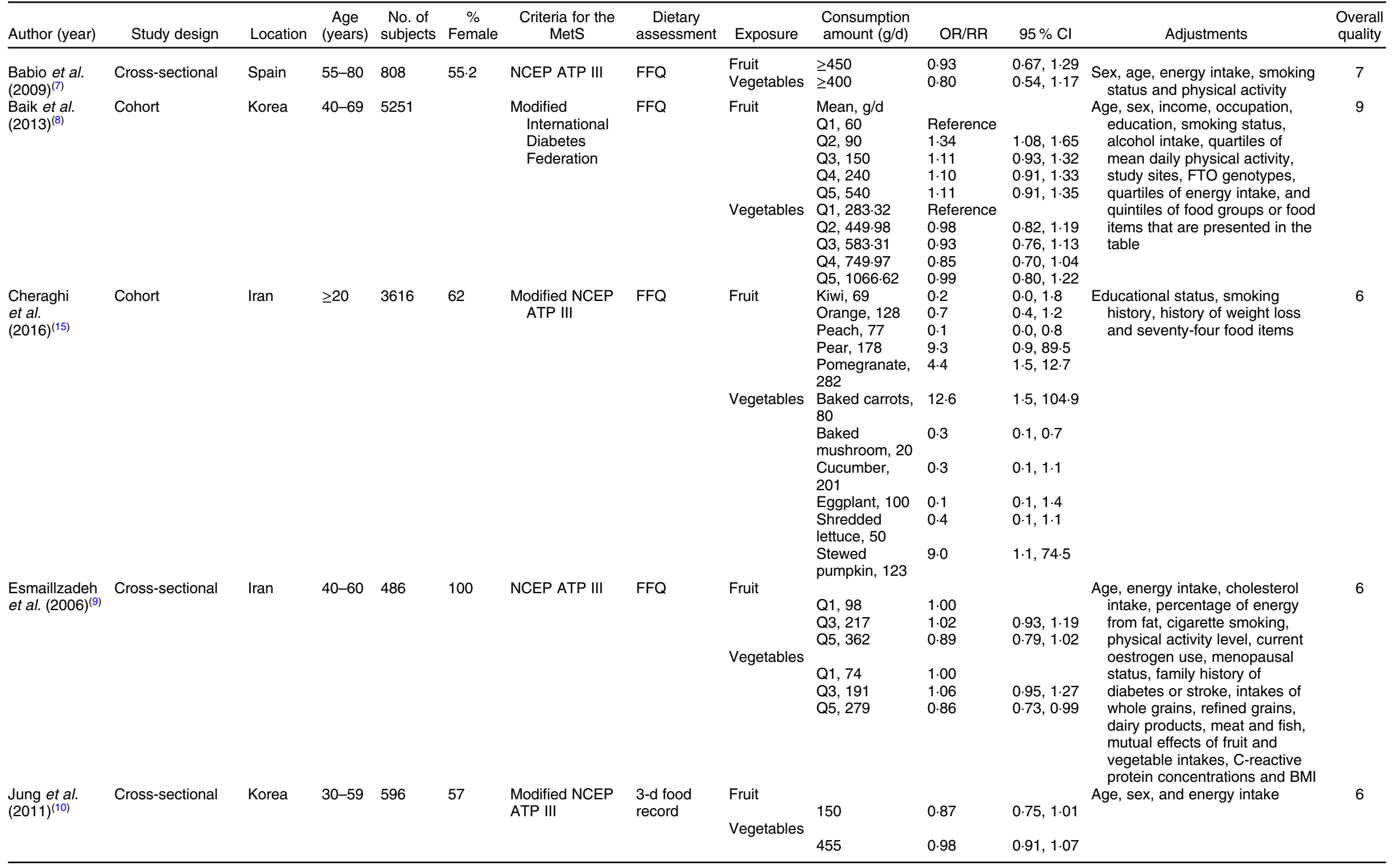


N British Journal of Nutrition

Table 1. Continued

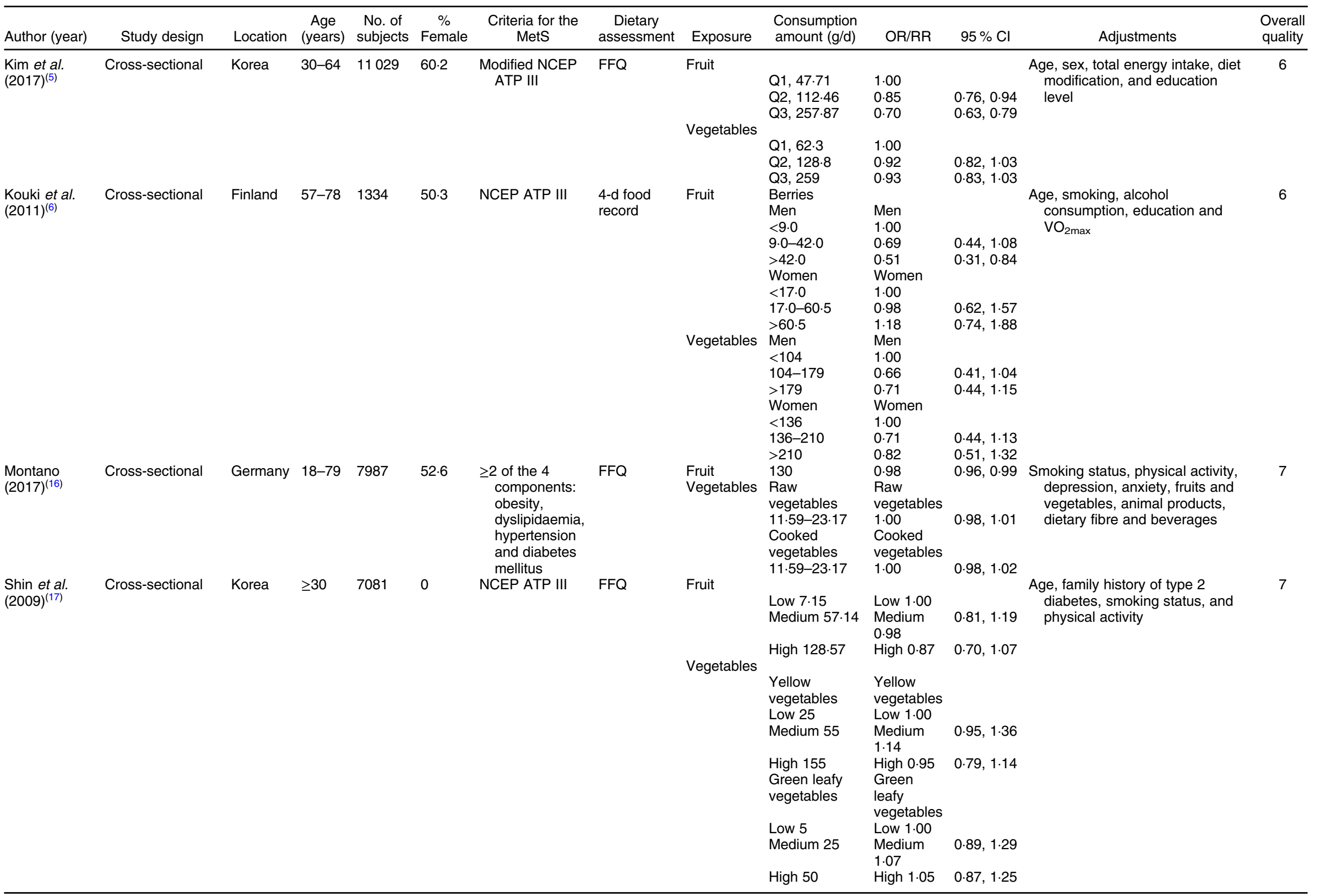

RR, relative risk; NCEP ATP III, National Cholesterol Education Program Adult Treatment Panel III; FTO, fat mass and obesity-associated. 


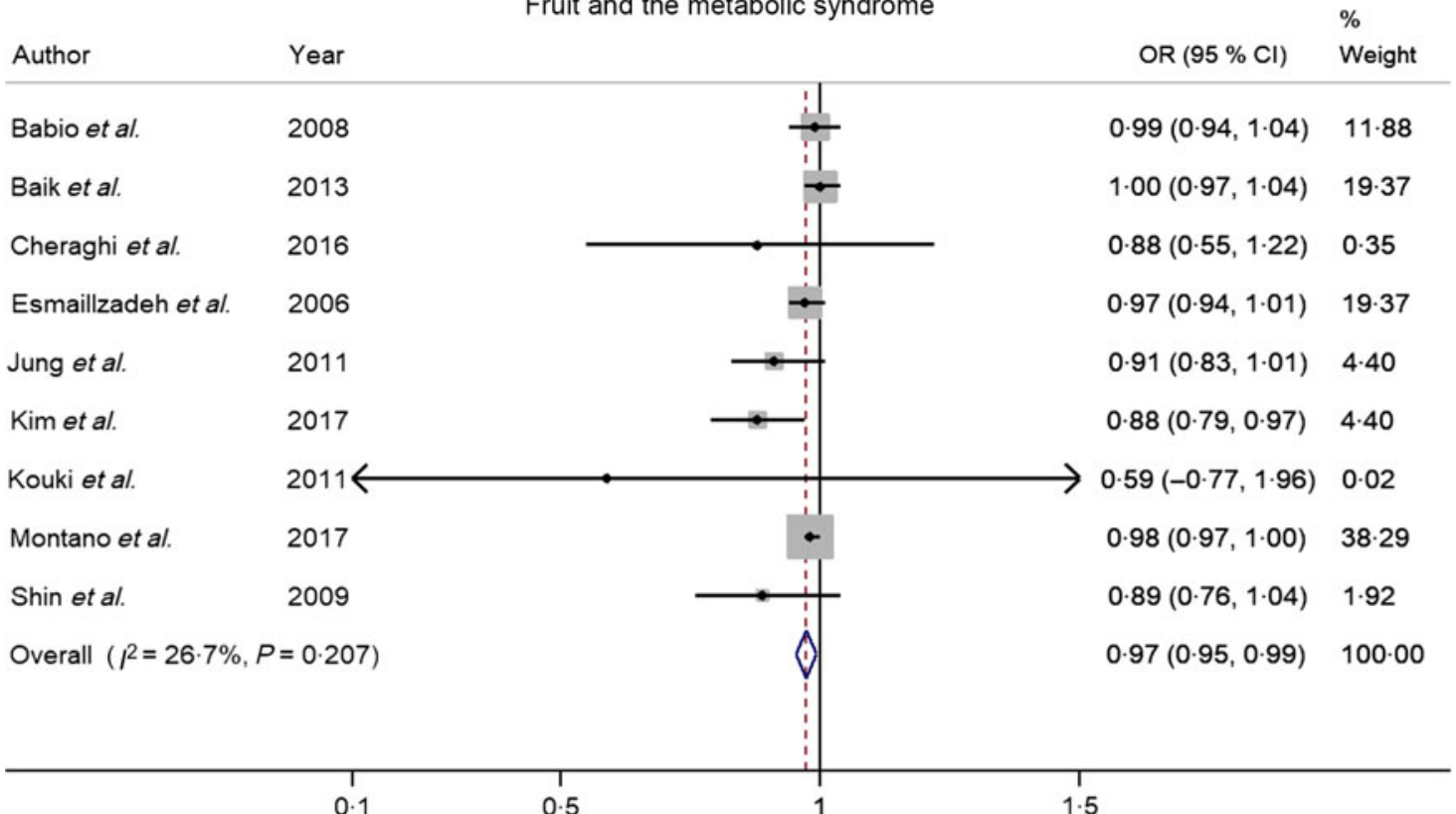

Vegetables and the metabolic syndrome

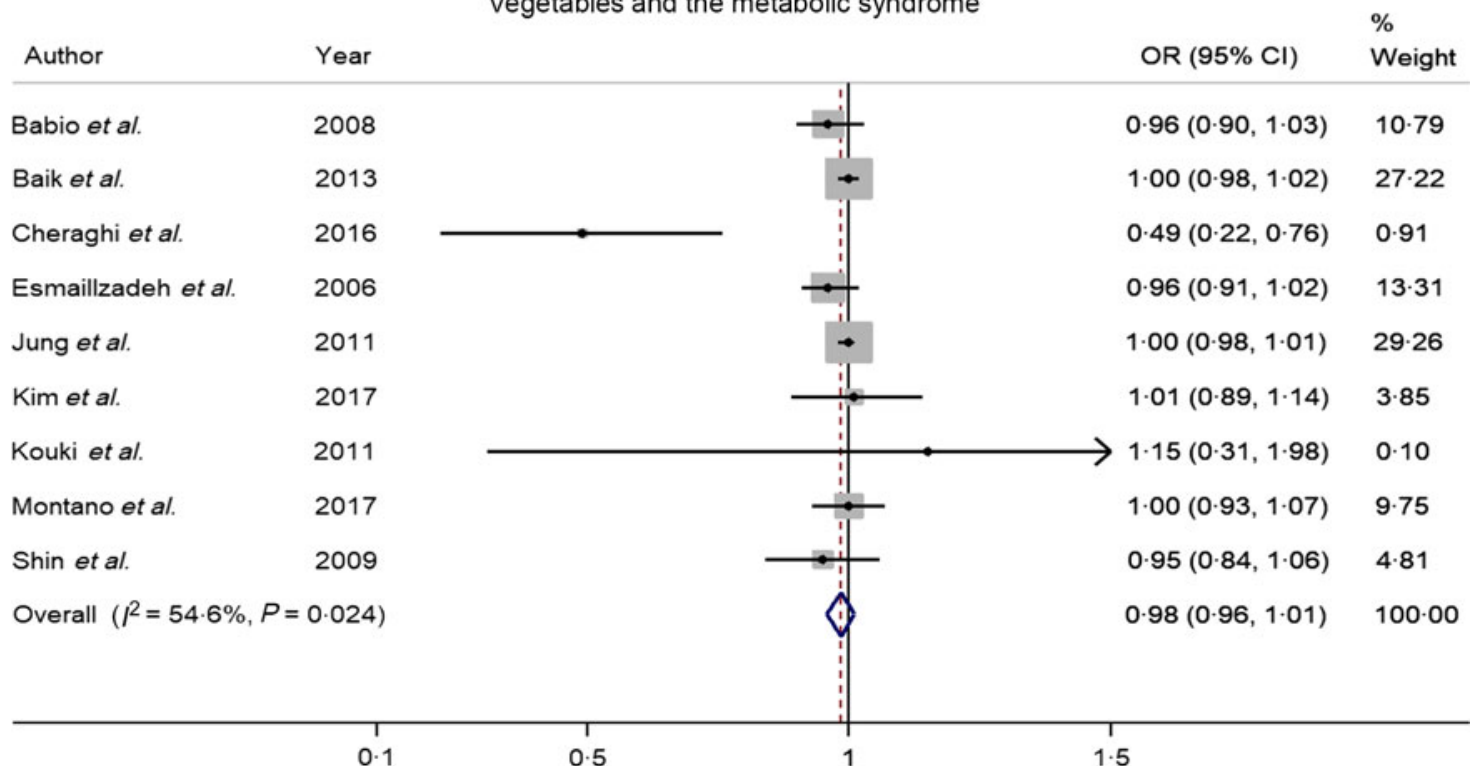

Fig. 2. Forest plot of the odds ratio of the metabolic syndrome per $100 \mathrm{~g} / \mathrm{d}$ increment in fruit or vegetable consumption.

in the lowest category of the fruit consumption was $0 \cdot 81$ (95\% CI $0.75,0.88)^{(12)}$. Another meta-analysis, including eight randomised controlled trials with 396 participants, reported that fruit intake was negatively associated with diastolic blood pressure in patients with the MetS (standardised mean differences $=-0.29 ; 95 \% \mathrm{CI}-0.57,-0 \cdot 02)^{(30)}$.

Mechanisms have been suggested to explain the beneficial effects of fruit intake on the MetS. Fruits have many nutrients, such as vitamins, minerals and phytochemicals, which have favourable effects on health outcome. Fruits contain abundant antioxidants such as vitamins $\mathrm{C}$ and $\mathrm{E}, \mathrm{Mg}, \mathrm{K}$, folic acid and phytochemicals. A higher intake of antioxidants can modulate oxidative stress by reducing levels of reactive oxygen species in both humans and animal models ${ }^{(31,32)}$. The protective effects of fruits against the MetS may be mediated through the effect of favourable components on inflammatory markers such as C-reactive protein and TNF- $\alpha^{(33,34)}$. Higher consumption of fruits is associated with a lower plasma level of C-reactive protein $^{(35)}$. Phytochemicals may also play a major role in preventing insulin resistance by increasing the body's production of insulin, which has a critical function in preventing the $\mathrm{MetS}^{(36)}$. Intake of fibre, which is abundant in fruits and vegetables, is also inversely associated with the $\operatorname{MetS}^{(37)}$.

Unlike in previous meta-analyses, vegetable intake was not significantly associated with the chance of the MetS in this dose-response meta-analysis. Two meta-analyses published 
Table 2. Subgroup analyses of fruit consumption and chance of the metabolic syndrome (MetS)

\begin{tabular}{|c|c|c|c|c|c|}
\hline Study & $\begin{array}{l}\text { No. of } \\
\text { studies }\end{array}$ & OR & $95 \% \mathrm{Cl}$ & Heterogeneity & $P^{*}$ \\
\hline All studies & 9 & 0.97 & $\begin{array}{l}0.95 \\
0.99\end{array}$ & $\begin{array}{l}P=0.21 \\
I^{2}=26.7 \%\end{array}$ & \\
\hline \multicolumn{6}{|l|}{ Study design } \\
\hline Cross-sectional & 7 & 0.97 & $\begin{array}{l}0.94 \\
0.99\end{array}$ & $\begin{array}{l}P=0.18 \\
I^{2}=32.3 \%\end{array}$ & 0.21 \\
\hline Cohort & 2 & 1.00 & $\begin{array}{l}0.96 \\
1.03\end{array}$ & $\begin{array}{l}P=0.49 \\
I^{2}=0.0 \%\end{array}$ & \\
\hline \multicolumn{6}{|l|}{ Study location } \\
\hline Asia & 6 & 0.95 & $\begin{array}{l}0.91 \\
0.99\end{array}$ & $\begin{array}{l}P=0.08 \\
I^{2}=49.5 \%\end{array}$ & 0.55 \\
\hline Europe & 3 & 0.98 & $\begin{array}{l}0.97 \\
1.00\end{array}$ & $\begin{array}{l}P=0.80 \\
I^{2}=0.00 \%\end{array}$ & \\
\hline \multicolumn{6}{|l|}{ MetS criteria } \\
\hline NCEP ATP III & 4 & 0.97 & $\begin{array}{l}0.94, \\
1.00\end{array}$ & $\begin{array}{l}P=0.55 \\
I^{2}=0.00 \%\end{array}$ & 0.70 \\
\hline Others & 5 & 0.97 & $\begin{array}{l}0.93 \\
1.00\end{array}$ & $\begin{array}{l}P=0.07 \\
I^{2}=53.7 \%\end{array}$ & \\
\hline \multicolumn{6}{|l|}{ Study quality } \\
\hline High & 4 & 0.98 & $\begin{array}{l}0.97 \\
1.00\end{array}$ & $\begin{array}{l}P=0.42 \\
I^{2}=0.00 \%\end{array}$ & 0.07 \\
\hline Others & 5 & 0.94 & $\begin{array}{l}0.90 \\
0.98\end{array}$ & $\begin{array}{l}P=0.31 \\
I^{2}=15.9 \%\end{array}$ & \\
\hline \multicolumn{6}{|c|}{ Adjustment for confounders } \\
\hline \multicolumn{6}{|l|}{ Alcohol } \\
\hline Yes & 2 & 1.00 & $\begin{array}{l}0.96 \\
1.03\end{array}$ & $\begin{array}{l}P=0.56 \\
I^{2}=0.00 \%\end{array}$ & 0.19 \\
\hline No & 7 & 0.97 & $\begin{array}{l}0.94 \\
0.99\end{array}$ & $\begin{array}{l}P=0.18 \\
I^{2}=32.3 \%\end{array}$ & \\
\hline \multicolumn{6}{|l|}{ Smoking } \\
\hline Yes & 7 & 0.98 & $\begin{array}{l}0.97 \\
0.99\end{array}$ & $\begin{array}{l}P=0.69 \\
I^{2}=0.00 \%\end{array}$ & 0.01 \\
\hline No & 2 & 0.90 & $\begin{array}{l}0.83 \\
0.96\end{array}$ & $\begin{array}{l}P=0.64 \\
I^{2}=0.00 \%\end{array}$ & \\
\hline \multicolumn{6}{|l|}{ Physical activity } \\
\hline Yes & 5 & 0.98 & $\begin{array}{l}0.97 \\
0.99\end{array}$ & $\begin{array}{l}P=0.51 \\
I^{2}=0.00 \%\end{array}$ & 0.01 \\
\hline No & 4 & 0.89 & $\begin{array}{l}0.83 \\
0.96\end{array}$ & $\begin{array}{l}P=0.94 \\
I^{2}=0.00 \%\end{array}$ & \\
\hline \multicolumn{6}{|l|}{ Education } \\
\hline Yes & 4 & 0.94 & $\begin{array}{l}0.85 \\
1.04\end{array}$ & $\begin{array}{l}P=0.09 \\
I^{2}=54.7 \%\end{array}$ & 0.62 \\
\hline No & 5 & 0.98 & $\begin{array}{l}0.96 \\
0.99\end{array}$ & $\begin{array}{l}P=0.38 \\
I^{2}=4.3 \%\end{array}$ & \\
\hline \multicolumn{6}{|c|}{ Family history of diabetes } \\
\hline Yes & 2 & 0.96 & $\begin{array}{l}0.91 \\
1.01\end{array}$ & $\begin{array}{l}P=0.28 \\
I^{2}=15.3 \%\end{array}$ & 0.44 \\
\hline No & 7 & 0.97 & $\begin{array}{l}0.95 \\
1.00\end{array}$ & $\begin{array}{l}P=0.17 \\
I^{2}=34.3 \%\end{array}$ & \\
\hline \multicolumn{6}{|l|}{ Energy intake } \\
\hline Yes & 5 & 0.97 & $\begin{array}{l}0.93 \\
1.00\end{array}$ & $\begin{array}{l}P=0.07 \\
I^{2}=53.8 \%\end{array}$ & 0.92 \\
\hline No & 4 & 0.98 & $\begin{array}{l}0.96 \\
0.99\end{array}$ & $\begin{array}{l}P=0.53 \\
I^{2}=0.0 \%\end{array}$ & \\
\hline \multicolumn{6}{|l|}{ Meat intake } \\
\hline Yes & 4 & 0.98 & $\begin{array}{l}0.97 \\
0.99\end{array}$ & $\begin{array}{l}P=0.60 \\
I^{2}=0.0 \%\end{array}$ & 0.17 \\
\hline No & 5 & 0.93 & $\begin{array}{l}0.87 \\
0.99\end{array}$ & $\begin{array}{l}P=0.16 \\
I^{2}=38.6 \%\end{array}$ & \\
\hline
\end{tabular}

NCEP ATP III, National Cholesterol Education Program Adult Treatment Panel III. ${ }^{*} P$ values for heterogeneity between subgroups with meta-regression analysis.

previously reported that the pooled OR for the MetS in the highest category of vegetable consumption were 11-15\% lower than those in the lowest category ${ }^{(11,12)}$. The present study included different publications from the previous studies because the
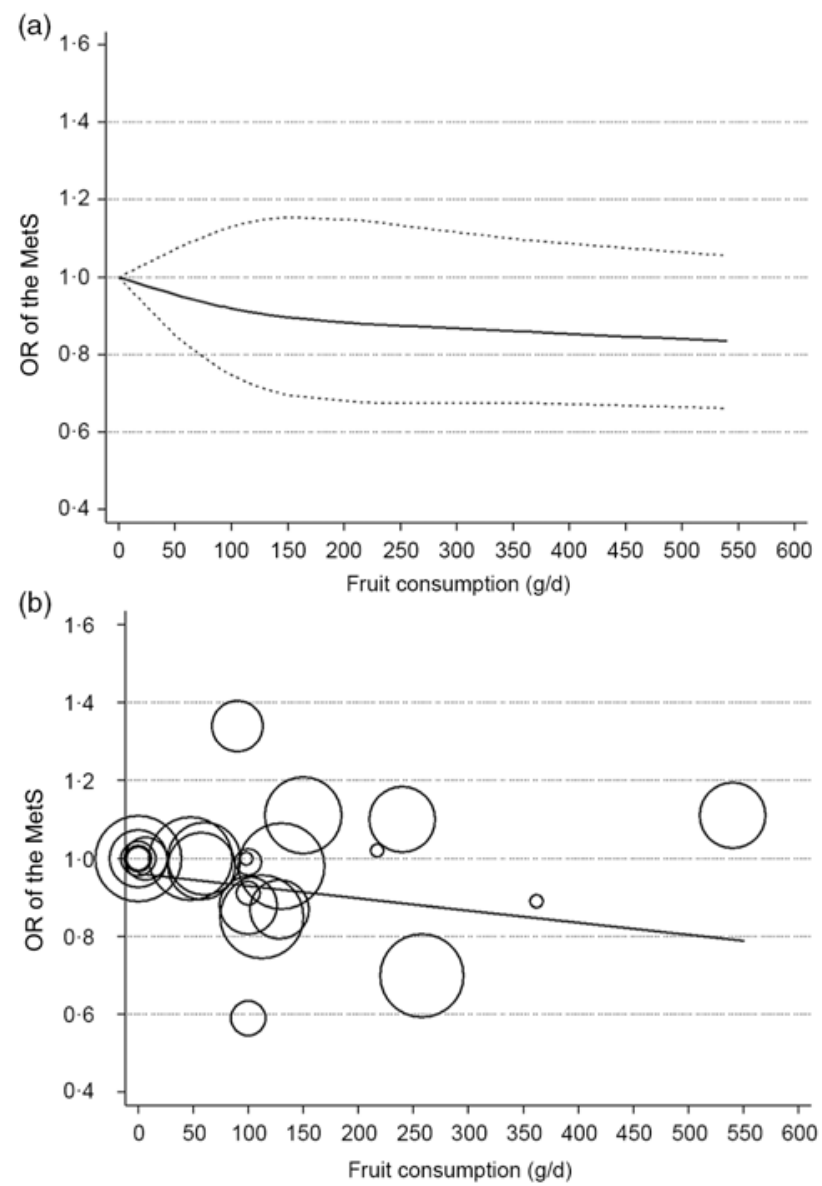

Fig 3. Association between the risk of the metabolic syndrome (MetS) and fruit consumption in observational studies in the meta-analyses. (a) Restricted cubic splines in a multivariate random-effects dose-response model. The solid curve represents estimates of the OR for the risk of the MetS across fruit consumption relative to a reference value of $0 \mathrm{~g} / \mathrm{d}$, and the dashed lines represent the $95 \% \mathrm{Cl}$ for the spline model. (b) Linear dose-response regression model. The solid line represents the weighted regression line, with weights proportional to the precision of the OR. The vertical axis is on a log scale.

present meta-analysis only included studies to provide data on the chance of the MetS (OR/RR and 95\% CI) according to vegetable intake to reveal a dose-response association. Also, the studies used different inclusion criteria and analytical methods for the data. The discrepancy in results may be due to differences in the variety of vegetables consumed or the cooking methods of vegetables consumed among studies. The biological effect of vegetables may vary with their variety ${ }^{(38)}$. Therefore, the consumption of different vegetable types might affect the association between vegetable consumption and risk of the MetS. Luo et al. found that the consumption of white vegetables, such as radish, sprouts and pumpkin was inversely associated with risk of cancer, while green vegetable intake was not ${ }^{(39)}$. A recent meta-analysis revealed that the total vegetable intake was associated with risk of the MetS, while green vegetable intake was not associated with the MetS in a subgroup analysis ${ }^{(12)}$. In addition, fruits are more commonly eaten raw than cooked, whereas vegetables are consumed after various cooking methods. 
Table 3. Subgroup analysis of vegetable consumption and chance of the metabolic syndrome (MetS)

\begin{tabular}{|c|c|c|c|c|c|}
\hline Study & $\begin{array}{l}\text { No. of } \\
\text { studies }\end{array}$ & OR & $95 \% \mathrm{Cl}$ & Heterogeneity & $P^{\star}$ \\
\hline All studies & 9 & 0.98 & $\begin{array}{l}0.96 \\
1.01\end{array}$ & $\begin{array}{l}P=0.02 \\
I^{2}=54.6 \%\end{array}$ & \\
\hline \multicolumn{6}{|l|}{ Study design } \\
\hline Cross-sectional & 7 & 1.00 & $\begin{array}{l}0.98 \\
1.01\end{array}$ & $\begin{array}{l}P=0.68 \\
I^{2}=0.00 \%\end{array}$ & 0.75 \\
\hline Cohort & 2 & 0.76 & $\begin{array}{l}0.27 \\
1.26\end{array}$ & $\begin{array}{l}P=0.00 \\
I^{2}=54.6 \%\end{array}$ & \\
\hline \multicolumn{6}{|l|}{ Study location } \\
\hline Asia & 6 & 0.98 & $\begin{array}{l}0.95 \\
1.02\end{array}$ & $\begin{array}{l}P=0.01 \\
I^{2}=69.3 \%\end{array}$ & 0.47 \\
\hline Europe & 3 & 0.98 & $\begin{array}{l}0.93 \\
1.03\end{array}$ & $\begin{array}{l}P=0.66 \\
I^{2}=0.00 \%\end{array}$ & \\
\hline \multicolumn{6}{|l|}{ MetS criteria } \\
\hline NCEP ATP III & 4 & 0.96 & $\begin{array}{l}0.92 \\
1.00\end{array}$ & $\begin{array}{l}P=0.97 \\
I^{2}=0.00 \%\end{array}$ & 0.10 \\
\hline Others & 5 & 0.99 & $\begin{array}{l}0.96 \\
1.03\end{array}$ & $\begin{array}{l}P=0.01 \\
I^{2}=70.8 \%\end{array}$ & \\
\hline \multicolumn{6}{|l|}{ Study quality } \\
\hline High & 4 & 1.00 & $\begin{array}{l}0.98 \\
1.01\end{array}$ & $\begin{array}{l}P=0.42 \\
I^{2}=0.00 \%\end{array}$ & 0.91 \\
\hline Other & 5 & 0.96 & $\begin{array}{l}0.88 \\
1.03\end{array}$ & $\begin{array}{l}P=0.31 \\
I^{2}=15.9 \%\end{array}$ & \\
\hline \multicolumn{6}{|c|}{ Adjustment for confounders } \\
\hline \multicolumn{6}{|l|}{ Alcohol } \\
\hline Yes & 2 & 1.00 & $\begin{array}{l}0.98 \\
1.02\end{array}$ & $\begin{array}{l}P=0.73 \\
I^{2}=0.00 \%\end{array}$ & 0.68 \\
\hline No & 7 & 0.97 & $\begin{array}{l}0.93 \\
1.01\end{array}$ & $\begin{array}{l}P=0.09 \\
I^{2}=65.2 \%\end{array}$ & \\
\hline \multicolumn{6}{|l|}{ Smoking } \\
\hline Yes & 7 & 0.96 & $\begin{array}{l}0.92 \\
1.01\end{array}$ & $\begin{array}{l}P=0.01 \\
I^{2}=64.3 \%\end{array}$ & 0.48 \\
\hline No & 2 & 1.00 & $\begin{array}{l}0.99 \\
1.02\end{array}$ & $\begin{array}{l}P=0.88 \\
I^{2}=0.00 \%\end{array}$ & \\
\hline \multicolumn{6}{|l|}{ Physical activity } \\
\hline Yes & 5 & 0.99 & $\begin{array}{l}0.97 \\
1.01\end{array}$ & $\begin{array}{l}P=0.49 \\
I^{2}=0.00 \%\end{array}$ & 0.53 \\
\hline No & 4 & 0.91 & $\begin{array}{l}0.73 \\
1.08\end{array}$ & $\begin{array}{l}P=0.00 \\
I^{2}=78.3 \%\end{array}$ & \\
\hline \multicolumn{6}{|l|}{ Education } \\
\hline Yes & 4 & 0.90 & $\begin{array}{l}0.73 \\
1.08\end{array}$ & $\begin{array}{l}P=0.00 \\
I^{2}=78.3 \%\end{array}$ & 0.72 \\
\hline No & 5 & 0.99 & $\begin{array}{l}0.98 \\
1.01\end{array}$ & $\begin{array}{l}P=0.44 \\
I^{2}=0.00 \%\end{array}$ & \\
\hline \multicolumn{6}{|c|}{ Family history of diabetes } \\
\hline Yes & 2 & 0.96 & $\begin{array}{l}0.91 \\
1.01\end{array}$ & $\begin{array}{l}P=0.87 \\
I^{2}=0.00 \%\end{array}$ & 0.12 \\
\hline No & 7 & 0.99 & $\begin{array}{l}0.96 \\
1.02\end{array}$ & $\begin{array}{l}P=0.02 \\
I^{2}=60.5 \%\end{array}$ & \\
\hline \multicolumn{6}{|l|}{ Energy intake } \\
\hline Yes & 5 & 1.00 & $\begin{array}{l}0.99 \\
1.01\end{array}$ & $\begin{array}{l}P=0.52 \\
I^{2}=0.00 \%\end{array}$ & 0.59 \\
\hline No & 4 & 0.88 & $\begin{array}{l}0.71 \\
1.06\end{array}$ & $\begin{array}{l}P=0.00 \\
I^{2}=77.1 \%\end{array}$ & \\
\hline \multicolumn{6}{|l|}{ Meat intake } \\
\hline Yes & 4 & 0.96 & $\begin{array}{l}0.89 \\
1.03\end{array}$ & $\begin{array}{l}P=0.00 \\
l^{2}=80.3 \%\end{array}$ & 0.85 \\
\hline No & 5 & 1.00 & $\begin{array}{l}0.98 \\
1.01\end{array}$ & $\begin{array}{l}P=0.69 \\
I^{2}=0.00 \%\end{array}$ & \\
\hline
\end{tabular}

NCEP ATP III, National Cholesterol Education Program Adult Treatment Panel III. ${ }^{*} P$ values for heterogeneity between subgroups with meta-regression analysis.

Vegetables are eaten steamed or boiled and mixed with a variety of seasonings, such as salt, pepper or dressing. These different cooking methods among various populations might influence the association between vegetable intake and chance of the MetS.

Between-study heterogeneity is common in meta-analysis. In the present study, the adjustment for smoking and physical activity was associated with heterogeneity. The effect of fruit consumption on the chance of the MetS was smaller in studies with adjustment for smoking or physical activity. Therefore, these potential risk factors for the MetS should be considered in the analysis of the association between dietary factors and risk of the MetS.

To the best of our knowledge, this is the first study to reveal a dose-response relationship between fruit or vegetable consumption and chance of the MetS. The present study provided quantitative data on the association between fruit consumption and chance of the MetS. A relatively large number of participants were included, which reduced the sampling error and enabled a much greater possibility of reaching reasonable conclusions. Most studies included in the meta-analysis were of good quality, and the included studies were analysed based on the most adjusted results. Most analyses had a very narrow $95 \% \mathrm{CI}$, and it proves that the estimates had high precision.

The study has some limitations. Most studies included in the meta-analysis were cross-sectional studies; large-scale cohort studies should be included to confirm the results. Although most of the included studies adjusted for most of the major confounding factors, there is a possibility of residual or unmeasured confounding factors on the association between fruit intake and the MetS, based on a rather small E-value $^{(40)}$. The use of different diagnosis criteria for the MetS, different methods of dietary assessment or a small study effect might affect the strength of the link between fruit or vegetable consumption and chance of the MetS. The potential for ecological bias exists since meta-analyses use aggregate data rather than analysing individual characteristics. Additionally, failure to identify non-linearity in the cubic spline models can result in overestimated or underestimated relationships.

In conclusion, the dose-response meta-analysis of observational studies showed that an increase of $100 \mathrm{~g} / \mathrm{d}$ in fruit consumption was associated with $3 \%$ lower odds of the MetS, but vegetable consumption was not associated with the MetS. For future research, a meta-analysis including cohort studies with high-quality or welldesigned randomised clinical trials should be conducted to confirm the association between fruit or vegetable intake and the risk of the MetS. Also, the effects of different varieties of fruits (e.g. citrus fruit, non-citrus fruit and carotene-rich fruit) and vegetables (e.g. green and white, cruciferous, carotene-rich and green leafy) on the risk of the MetS should be examined.

\section{Supplementary material}

For supplementary material/s referred to in this article, please visit https://doi.org/10.1017/S000711451900165X

\section{Acknowledgements}

This research was supported by the Basic Science Research Program of the National Research Foundation of Korea (NRF), 
funded by the Ministry of Education, Science, and Technology (NRF2017 R1D1A1B03931307). The NRF had no role in the study design, data analysis, or writing of this article.

All of the authors had a significant role in the study. M. L. contributed to the data analysis and manuscript writing. M. L. contributed to the literature search and data analysis. J. K. contributed to research design and manuscript writing; she has the primary responsibility for the final content. All authors read and approved the final manuscript.

The authors declare that there are no conflicts of interest

\section{References}

1. Lutsey PL, Steffen LM \& Stevens J (2008) Dietary intake and the development of the metabolic syndrome: the Atherosclerosis Risk in Communities study. Circulation 117, 754-761.

2. McCracken E, Monaghan M \& Sreenivasan S (2018) Pathophysiology of the metabolic syndrome. Clin Dermatol 36, 14-20.

3. Chung SJ, Lee Y, Lee S, et al. (2015) Breakfast skipping and breakfast type are associated with daily nutrient intakes and metabolic syndrome in Korean adults. Nutr Res Pract 9, 288-295.

4. Aune D, Giovannucci E, Boffetta P, et al. (2017) Fruit and vegetable intake and the risk of cardiovascular disease, total cancer and all-cause mortality - a systematic review and dose-response meta-analysis of prospective studies. Int J Epidemiol 46, 1029-1056.

5. Kim OY, Kwak SY, Kim B, et al. (2017) Selected food consumption mediates the association between education level and metabolic syndrome in Korean adults. Ann Nutr Metab 70, 122-131.

6. Kouki R, Schwab U, Hassinen M, et al. (2011) Food consumption, nutrient intake and the risk of having metabolic syndrome: the DR's EXTRA study. Eur J Clin Nutr 65, 368-377.

7. Babio N, Bullo M, Basora J, et al. (2009) Adherence to the Mediterranean diet and risk of metabolic syndrome and its components. Nutr Metab Cardiovasc Dis 19, 563-570.

8. Baik I, Lee M, Jun NR, et al. (2013) A healthy dietary pattern consisting of a variety of food choices is inversely associated with the development of metabolic syndrome. Nutr Res Pract 7, 233-241.

9. Esmaillzadeh A, Kimiagar M, Mehrabi Y, et al. (2006) Fruit and vegetable intakes, C-reactive protein, and the metabolic syndrome. Am J Clin Nutr 84, 1489-1497.

10. Jung HJ, Han SN, Song S, et al. (2011) Association between adherence to the Korean Food Guidance System and the risk of metabolic abnormalities in Koreans. Nutr Res Pract 5 , $560-568$

11. Tian Y, Su L, Wang J, et al. (2018) Fruit and vegetable consumption and risk of the metabolic syndrome: a meta-analysis. Public Health Nutr 21, 756-765.

12. Zhang $Y \&$ Zhang DZ (2018) Associations of vegetable and fruit consumption with metabolic syndrome. A meta-analysis of observational studies. Public Health Nutr 21, 1693-1703.

13. Modesti PA, Reboldi G, Cappuccio FP, et al. (2016) Panethnic differences in blood pressure in Europe: a systematic review and meta-analysis. PLOS ONE 11, e0147601.

14. DerSimonian R \& Laird N (1986) Meta-analysis in clinical trials. Control Clin Trials 7, 177-188.

15. Cheraghi Z, Mirmiran P, Mansournia MA, et al. (2016) The association between nutritional exposures and metabolic syndrome in the Tehran Lipid and Glucose Study (TLGS): a cohort study. Public Health 140, 163-171.

16. Montano D (2017) Association between socioeconomic determinants and the metabolic syndrome in the German Health Interview and Examination Survey for Adults (DEGS1) - a mediation analysis. Rev Diabet Stud 14, 279-294.

17. Shin A, Lim SY, Sung J, et al. (2009) Dietary intake, eating habits, and metabolic syndrome in Korean men. J Am Diet Assoc 109, 633-640.

18. Greenland S \& Longnecker MP (1992) Methods for trend estimation from summarized dose-response data, with applications to meta-analysis. Am J Epidemiol 135, 1301-1309.

19. Orsini N, Bellocco R \& Greenland S (2006) Generalized least squares for trend estimation of summarized dose-response data. Stata J 6, 40-57.

20. Harrell FE Jr, Lee KL \& Pollock BG (1988) Regression models in clinical studies: determining relationships between predictors and response. J Natl Cancer Inst 80, 1198-1202.

21. Durrleman S \& Simon R (1989) Flexible regression models with cubic splines. Stat Med $\mathbf{8}, 551-561$.

22. Smith PL (1979) Splines as a useful and convenient statistical tool. Am Stat 33, 57-62.

23. Higgins JP \& Thompson SG (2002) Quantifying heterogeneity in a meta-analysis. Stat Med 21, 1539-1558.

24. Higgins JP, Thompson SG, Deeks JJ, et al. (2003) Measuring inconsistency in meta-analyses. BMJ 327, 557-560.

25. Egger M, Davey Smith G, Schneider M, et al. (1997) Bias in meta-analysis detected by a simple, graphical test. BMJ $\mathbf{3 1 5}$, 629-634.

26. Sterne JA, Sutton AJ, Ioannidis JP, et al. (2011) Recommendations for examining and interpreting funnel plot asymmetry in metaanalyses of randomised controlled trials. BMJ 343, d4002.

27. Furuya-Kanamori L, Barendregt JJ \& Doi SA (2018) A new improved graphical and quantitative method for detecting bias in meta-analysis. Int J Evid Based Healthc 16, 195-203.

28. National Cholesterol Education Program Expert Panel on Detection Evaluation Treatment of High Blood Cholesterol in Adults (2002) Third report of the National Cholesterol Education Program (NCEP) expert panel on detection, evaluation, and treatment of high blood cholesterol in adults (Adult Treatment Panel III) final report. Circulation 106, 3143-3421.

29. International Diabetes Federation Clinical Guidelines Task Force (2006) Global guideline for type 2 diabetes: recommendations for standard, comprehensive, and minimal care. Diabet Med 23, 579-593.

30. Shin JY, Kim JY, Kang HT, et al. (2015) Effect of fruits and vegetables on metabolic syndrome: a systematic review and metaanalysis of randomized controlled trials. Int J Food Sci Nutr $\mathbf{6 6}$, 416-425.

31. Khalil A, Gaudreau P, Cherki M, et al. (2011) Antioxidant-rich food intakes and their association with blood total antioxidant status and vitamin $\mathrm{C}$ and $\mathrm{E}$ levels in community-dwelling seniors from the Quebec longitudinal study NuAge. Exp Gerontol 46, 475-481.

32. Bokov A, Chaudhuri A \& Richardson A (2004) The role of oxidative damage and stress in aging. Mech Ageing Dev 125, 811-826.

33. Watzl B, Kulling SE, Moseneder J, et al. (2005) A 4-wk intervention with high intake of carotenoid-rich vegetables and fruit reduces plasma C-reactive protein in healthy, nonsmoking men. Am J Clin Nutr 82, 1052-1058.

34. Hermsdorff HH, Zulet MA, Puchau B, et al. (2010) Fruit and vegetable consumption and proinflammatory gene expression from peripheral blood mononuclear cells in young adults: a translational study. Nutr Metab (Lond) 7, 42. 
35. Mahoney SE \& Loprinzi PD (2014) Influence of flavonoidrich fruit and vegetable intake on diabetic retinopathy and diabetes-related biomarkers. J Diabetes Complications 28, 767-771.

36. Jayaprakasam B, Vareed SK, Olson LK, et al. (2005) Insulin secretion by bioactive anthocyanins and anthocyanidins present in fruits. J Agric Food Chem 53, 28-31.

37. Chen JP, Chen GC, Wang XP, et al. (2017) Dietary fiber and metabolic syndrome: a meta-analysis and review of related mechanisms. Nutrients 10, 24.
38. Park S, Ham JO \& Lee BK (2015) Effects of total vitamin A, vitamin $\mathrm{C}$, and fruit intake on risk for metabolic syndrome in Korean women and men. Nutrition 31, 111-118.

39. Luo WP, Fang YJ, Lu MS, et al. (2015) High consumption of vegetable and fruit colour groups is inversely associated with the risk of colorectal cancer: a case-control study. Br J Nutr 113, 1129-1138.

40. VanderWeele TJ \& Ding P (2017) Sensitivity analysis in observational research: introducing the E-value. Ann Intern Med 167, 268-274. 